\title{
Influence of Sijiqing Decoction on Rats with Traumatic Ulcer
}

\author{
Ming BAI, Yan LI, Ting WANG, Tan WANG, Pengran HAN, MingSan MIAO* \\ Henan College of Traditional Chinese Medicine, Henan Zhengzhou 450008, China
}

\begin{abstract}
Objective: To investigate the effect of external use of Sijiqing Decoction (SD) on rats with traumatic ulcer. Methods: With special injuries is at the right side of the spine punch traumatic ulcer model in rats, observe the high, medium and low dose of sijiqing decoction of traumatic ulcer area and ulcer of rats in the form of local tissue. Results: Compared with the model group, On the third day of administration, high and medium dose of SD group could significantly reduce the rat traumatic ulcer area, on the seventh and tenth day of administration, each dose of SD group can significantly reduce the area of traumatic ulcer on rats; Compared with the model group, the dose of SD group could significantly improve the pathological changes of rat traumatic ulcer model of local skin. Conclusion: SD external have a very good therapeutic effect on rats with traumatic ulcer.
\end{abstract}

KEYWORD: Sijiqing Decoction; Rats; Traumatic ulcer

\section{INTRODUCTION}

The dry leaves of Sijiqing for Holly plants Ilex chinensis Sims, which was contained in the Tang "herbal supplements". Cool, bitter taste, slightly astringent. With heat clearing and detoxicating, cooling blood to stop bleeding, myogenic convergence effect and so on. Mainly used for the treatment of pneumonia, acute throat inflammation, diarrhea, infection of biliary tract, external treatment of burns, lower limb ulcer, dermatitis, eczema, chapped hands and feet etc [1]. Effect of external treatment of simple modern clinical type of chronic suppurative otitis media, burn and scald, relatively superficial pyogenic infection of soft tissues and other symptoms of exact [2]. Modern research shows that Sijiqing has obvious antimicrobial action of against Staphylococcus aureus and Pseudomonas aeruginosa[3]. The 2010 version Pharmacopoeia recorded in the product external treatment of burns, skin ulcers, but the clinical external function did not have the corresponding reflected in the Pharmacopoeia. The experimental observation of the effect of Sijiqing decoction on rat model of traumatic ulcer, in the discussion of Sijiqing external function.

\section{EXPERIMENTAL MATERIALS}

\subsection{Animal}

Wistar rat, male and female, Weight $180 \sim 220 \mathrm{~g}$, supplied by the Experimental Animal Center of Hebei Medical. Animal permit number: 1202047. Laboratory Certificate of Conformity: SYXK (Henan) 2010-001.

\subsection{Drugs and reagents}

Sijiqing from Anhui, Bozhou, which by the Henan University of Traditional Chinese Medicine Department of Pharmacognosy identified as dried leaves of Ilex chinensis Sims. Sijiqing decoction preparation: Sijiqing medicine $600 \mathrm{~g}, 10$ times the amount of distilled water for 30 min after decoction, with simmer in $60 \mathrm{~min}$ after boiling, leach solution and adding 8 times amount of water, simmered in 60 min after boiling, leach solution, a total of two Fried, merge the filtrate, $70{ }^{\circ} \mathrm{C}$ concentrated to crude drug content in high, medium and low dose of $1.5 \mathrm{~g} \cdot \mathrm{ml}-$ $1,1.0 \mathrm{~g} \bullet \mathrm{ml}-1,0.5 \mathrm{~g} \bullet \mathrm{ml}-1$ and drug filling after cold preservation; Jingwanhong, Tianjin Darentang Jingwanhong Pharmaceutical Company Limited, production batch number 211793; Chloral hydrate, development center of tianjin branch close the chemical reagent, production batch number 20091018; Sodium Chloride Injection, Henan Huali pharmaceutical Limited by Share Ltd, production 
batch number c11101501; Qiaomier depilatory creams, Guangzhou Yibai Ya cosmetics Co., Ltd., production batch number 20110321 .

\section{EXPERIMENTAL METHODS}

\subsection{Rats with traumatic ulcer models and target detection}

60 Wistar rats, male and female, Weight $180 \sim 220 \mathrm{~g}$, which were randomly selected 10 for the control group and the remaining rats modeling. The rats were first back hair removal $(3 \mathrm{~cm} * 3 \mathrm{~cm})$, anesthesia, and then $1.5 \mathrm{~cm}$ with punch in the dorsal central spinal rat right side, cutting 1 round ulcer $(1.8 \mathrm{~cm}$ diameter, area of $2.54 \mathrm{~cm}^{2}$ ), remove the subepidermal tissue to the muscle fascia, hemostasis after the backup [4]. Rats in the first two days after building to raise only 3-4 per cage, each group of three cages, free to eat, the water recovery for each cage 10 only a set of $3 \mathrm{~d}$. The next day, give a medication before with physiological saline cleaning wounds, dry sterile gauze. Choose to build successful and modeling consistent 50 rats (male and female), were divided into 5 groups respectively, in the external application of large, small dose of Sijiqing Decoction $\left(1.5,1.0,0.5 \mathrm{~g} \bullet \mathrm{ml}^{-1}\right.$, thickness of $2 \mathrm{~mm}$, the equivalent of $0.5 \mathrm{ml} \cdot \mathrm{cm}^{-2}$ ), Jingwangong group (thickness of $2 \mathrm{~mm}$, the equivalent of $0.1 \mathrm{~g} \cdot \mathrm{cm}^{-2}$ ), model group apply with physiological saline volume $\left(0.5 \mathrm{ml} \cdot \mathrm{cm}^{-2}\right)$; The control group treated with the model group. All groups after administration were cover with plastic wrap and adhesive tape fixed, continuous not break when dosing, maintain the drugs in contact with the skin 6h every day, after administration of $6 \mathrm{~h}$, with $0.9 \%$ Sodium Chloride Injection wash drug; once a day continuous dressing, dressing 12D.

Each group of rat 1-10, made after the success of the mould, chitin from 3, 7, $10 \mathrm{~d}$ cover ulcer surface along with vegetable parchment and edge trace, cutting film, buy to analysis the balance quality conversion area, observe its ulcer healing situation before (eeg, wash cut with physiological saline), taking pictures at the same time, in the final $1 \mathrm{~h}$ after the treatment the rats weighing, put to death in the rat, take wound granulation tissue and the healing area center organization, fixed with formalin solution, dehydration, paraffin embedding, sectioning, routine HE staining[5].

\subsection{Methods Statistical Analysis}

Data analysis used SPSS 13.0 for windows for statistical treatment. measurement data represented by mean \pm variance $(\overline{\mathrm{x}} \pm s)$, group comparison used analysis of variance; ranked data used Ridit test.

\section{RESULTS}

Effects of rats with traumatic ulcer model of is shown in Table 1

Table 1 Effect of Sijiqing decoction used externally on rat with traumatic ulcer model of ulcer area

\begin{tabular}{|c|c|c|c|c|}
\hline \multirow{2}{*}{ Group } & \multirow{2}{*}{$\mathrm{N}$} & \multicolumn{3}{|c|}{ The ulcer area $\left(\mathrm{cm}^{2}\right)$} \\
\hline & & $3 d$ & $7 d$ & $10 \mathrm{~d}$ \\
\hline $\begin{array}{l}\text { The blank } \\
\text { group }\end{array}$ & 10 & $0.0 \pm 0.0 * *$ & $0.0 \pm 0.0 * *$ & $0.0 \pm 0.0 * *$ \\
\hline $\begin{array}{l}\text { The model } \\
\text { group }\end{array}$ & 10 & $1.90 \pm 0.29$ & $1.43 \pm 0.12$ & $0.84 \pm 0.14$ \\
\hline $\begin{array}{l}\text { Jingwanhong } \\
\text { group }\end{array}$ & 10 & $1.39 \pm 0.23 * *$ & $0.57 \pm 0.19 * *$ & $0.19 \pm 0.09 * *$ \\
\hline $\begin{array}{l}\text { High dose of } \\
\text { SD Group }\end{array}$ & 10 & $1.47 \pm 0.20 * *$ & $0.65 \pm 0.15^{* *}$ & $0.23 \pm 0.01 * *$ \\
\hline $\begin{array}{l}\text { Medium } \\
\text { doses of SD } \\
\text { group }\end{array}$ & 10 & $1.53 \pm 0.23 * *$ & $0.72 \pm 0.18 * *$ & $0.36 \pm 0.10^{* *}$ \\
\hline $\begin{array}{l}\text { Low dose of } \\
\text { SD Group }\end{array}$ & 10 & $1.68 \pm 0.19$ & $1.05 \pm 0.11 * *$ & $0.56 \pm 0.11 * *$ \\
\hline
\end{tabular}

Note: Compared with the model group, $* \mathrm{P}<0.05, * * \mathrm{P}<0.01$

From table 1, significantly higher ulcer area before administration of each group were compared with the blank group, the ulcer area of other groups don't have marked disparity, which demonstrate that the grouping is uniform. Compared with the blank group, the level of ulcer area in third, seventh and tenth day was remarkably increased $(\mathrm{P}<0.01)$, shows that the model copied successfully. Compared with the model group, in third day, the high, medium dose of SD and Jingwanhong group could remarkably reduce the level of ulcer area $(\mathrm{P}<0.01)$; in seventh and tenth day, each dose of SD group and Jingwanhong group could remarkably reduce the level of ulcer area $(\mathrm{P}<0.01)$.

Effects on rat with traumatic ulcer model of ulcer local tissue morphology is shown in Table 2

The experimental group histopathological observation results are as follows: The rats in the blank group ulcer local skin tissue visible epithelial cells of normal subcutaneous tissue, basically normal, see figure 1; The rats in the model group ulcer local skin tissue visible epithelial cells disappeared, subcutaneous tissue of a large number of inflammatory cell infiltration, deep tissue granulation tissue, see Figure 2, 3; Jingwanhong group rat ulcer local skin tissue visible keratinized epithelial cell hyperplasia, subcutaneous tissue showed granulation tissue in large numbers, see Figure 4, 5; The high dose of SD group rats ulcer local skin tissue visible keratinized epithelial cell hyperplasia, there are a lot of granulation tissue in the subcutaneous tissue, see Figure 6, 7; Medium doses of SD group rats ulcer local skin tissue visible 
keratinized epithelial cell hyperplasia, subcutaneous tissue in a large number of inflammatory cell infiltration, deep tissue appeared granulation tissue, see Figure 8, 9; Low doses of SD group rat ulcer local skin tissue visible epithelial cells disappeared, a large number of inflammatory cells infiltration and congestion in the subcutaneous tissue, deep tissue granulation tissue, see Figure 10, 11.

Table 2 Effect of pathological changes of on rats with traumatic ulcer model.

\begin{tabular}{|c|c|c|c|c|c|}
\hline Group & $\mathrm{N}$ & - & + & ++ & ++ \\
\hline $\begin{array}{c}\text { The blank } \\
\text { group }\end{array}$ & 10 & 10 & 0 & 0 & 0 \\
\hline $\begin{array}{c}\text { The model } \\
\text { group }\end{array}$ & 10 & 0 & 0 & 0 & 10 \\
\hline $\begin{array}{c}\text { Jingwanhong } \\
\text { group }\end{array}$ & 10 & 0 & 8 & 2 & 0 \\
\hline $\begin{array}{c}\text { High dose of } \\
\text { SD Group }\end{array}$ & 10 & 0 & 8 & 2 & 0 \\
\hline $\begin{array}{c}\text { Medium } \\
\text { dose of SD } \\
\text { group }\end{array}$ & 10 & 0 & 6 & 4 & 0 \\
\hline $\begin{array}{c}\text { Low dose of } \\
\text { SD Group }\end{array}$ & 10 & 0 & 0 & 8 & 2 \\
\hline
\end{tabular}

"-" the epithelial cells of normal, subcutaneous tissue is basic and normal; "+" epithelial thickening keratosis hyperplasia, subcutaneous tissue showed granulation tissue; "+ +" epithelial thickening keratosis subcutaneous tissue hyperplasia, inflammatory cell infiltration and deep tissue showed granulation tissue; " +++ " epithelial cells disappeared, a large number of inflammatory cells infiltration and congestion subcutaneous tissue, deep tissue showed granulation tissue. The main pathological change the experiment above skin tissue ulceration and a large number of inflammatory cells infiltration and congestion, deep formation organization seen with granulation tissue is the main pathological features.

From table 2, the analysis by Ridit test, Compared with the blank group, the level of Traumatic ulcer pathological damage was remarkably increased $(\mathrm{P}<0.01)$, shows that the model copied successfully. Compared with the model group, Each dose of SD group and the Jingwanhong group could remarkably a pathological changes of rat traumatic ulcer model of local skin $(\mathrm{P}<0.01)$, especially the high dose of SD group and Jingwanhong group.

\section{DISCUSSION}

Traumatic ulcer is clinical frequently encountered disease, cause of limb blood circulation disorder due to trauma, local skin necrosis and formation of prolonged does not heal the ulcer wound, occurred in the surface, has the characteristics of long duration, bad appearance and complications, so it exists on the patient's life and work quality caused great harm has been caused by the wound, engaged in medical workers attach great importance[6-7].
Although currently has developed a variety of epidermal growth factor, external preparation such as biologic protein sponge are used in clinical, from the clinical efficacy of these drugs is good for fresh wounds and wound healing, but to chronic, chronic ulcer and wound effect is not ideal, and therefore there are many scholars study the use of traditional Chinese medicine external treatment to treat traumatic ulcer, satisfactory results have been achieved[8-10].

This experiment adopts the rat model of trauma injury is caused by adopting special punch, local ulceration, pus, model consistent with the clinical symptom of skin ulcer had made this method, is simple and convenient in operation and high repeatability. For the better curative effect judgment on Sijiqing external skin trauma, this experiment was evaluated of traumatized area and local tissue morphology. Trauma wounds local area show the extent of damage, reflect the ability of drugs to promote wound healing; local tissue changes may reflect the damaged tissue layers of the skin inflammatory cell infiltration and healing, a direct reflection of drug efficacy.

The results of the study showed that each dose of SD can be reduced the rats with traumatic ulcer area, indicating that Sijiqing has pharmacological effects antibacterial, anti-inflammatory. Impact on the ulcer area, in third day, the high and medium doses of SD group could remarkably reduce the level of ulcer area. in seventh and tenth day, each dose of SD group could remarkably reduce the level of ulcer area. Impact of traumatic ulcer model in rats pathological aspects, Each dose of SD group can significantly improve the pathological changes of the traumatic ulcer rat skin, prompting ulcers gap closed tissue repair, reduce inflammatory cells infiltration; Prompt Sijiqing Decoction for external use has good healing sore myogenic effect, topical treatment of traumatic ulcer needs the accumulation of time.

\section{REFERENCES}

[1] Zhang YM, Li CH. Chinese medicine in Sijiqing. Jilin Journal of traditional Chinese medicine, 2010, 30 (3): 2522.

[2] Zhen HS, Li SM, Dong JZ. Advances in studies on chemical constituents and pharmacological action of Sijiqing. progress in research of traditional Chinese medicine, 2007, 24 (6): 18-20.

[3] Xie JB, Li P. Studies on the chemical constituents of phenolic acids in Sijiqing. Journal of China Medicine University, 2001,33 (1): 76-77.4 LUO Y H, HAN X M, CHANG F R. Study on the pharmacologic function of Quyushengjigao on rat with pyogenic infection and uceration of skin. Chin J Tradit Med Sci Technol, 2002, 9(5): 283-284.

[4] LUO Y H, HAN X M, CHANG F R. Study on the pharmacologic function of Quyushengjigao on rat with 
pyogenic infection and uceration of skin. Chin J Tradit Med Sci Technol (China Chinese medicine science and Technology), 2002, 9 (5): 283-284.

[5] Han XM, Luo YH, Shi YF. Study on the treatment of chronic ulcer of skin Pyocutaneous model test. Journal of Liaoning University of Traditional Chinese Medicine, 2009, 11 (5): 207-209.

[6] Bo ZY, Gan MM, Yuan CS, et al. Clinical efficacy of. 2013, 27 nursing research observation of self-made ulcers healing ointment in the treatment of traumatic ulcer (7): 1958-1960.

[7] Miao MS, Liu DD, Jia JJa, Guo X, Xiao K. The Antiinflammatory Effect of external use and the Impact on
Scalded Mice Model of Arisaema, WIT Transactions on Biomedicine and Health, 2013, 18(1):169.

[8] Yang JH. Yellow ice sheet powder topical treatment of traumatic ulcer. external treatment of traditional Chinese medicine journal, 2007, 16 (2): 398.

[9] Jing G, Xiong Y, Yi HC, et al. Compound Gongying liquid topical treatment experience of 78 cases of traumatic ulcer. Journal of Guiyang College of Traditional Chinese Medicine, 2009, 21 (3): 40-41.

[10] Pan XY, Lao DQ. Observe the efficacy of MEBO topical oxygen therapy combined with chronic ulcer of skin care in the. 2011, 9 family (4A): 877-878

\section{APPENDIX}

Observation of the pathological Sijiqing picture on rats with traumatic ulcer model

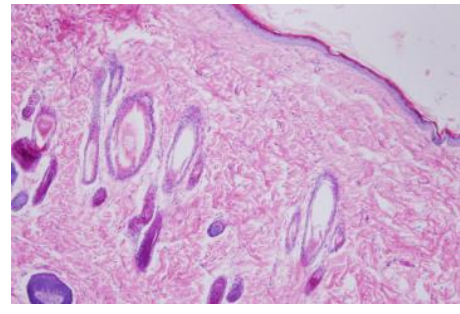

Picture 1 The blank group HE*100

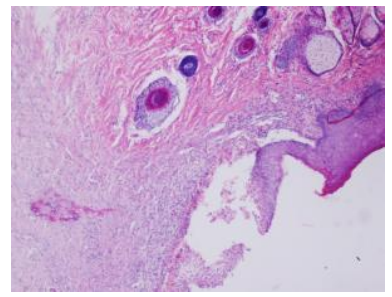

Picture 4 Jingwanhong group HE*100

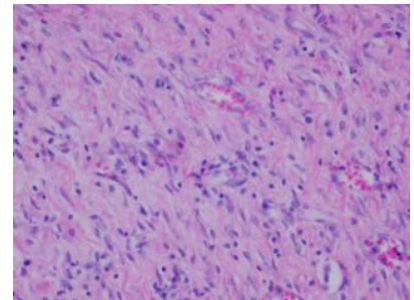

Picture 7 large dose of SD group $\mathrm{HE} * 400$

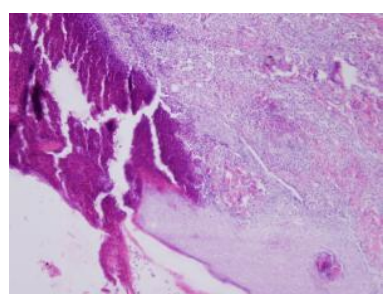

Picture 10 small dose of SD group $\mathrm{HE} * 100$

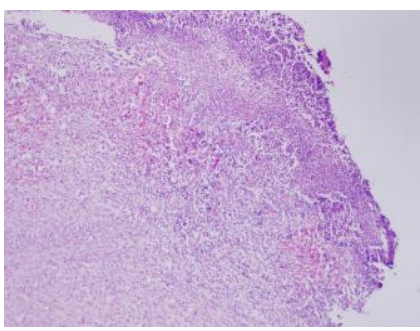

Picture 2 The model group $\mathrm{HE} * 100$

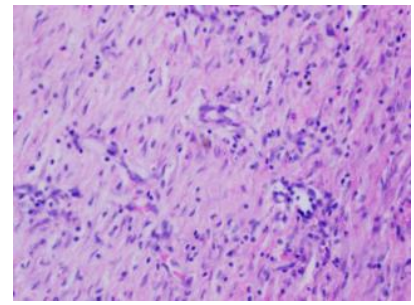

Picture 5 Jingwanhong group $\mathrm{HE} * 400$

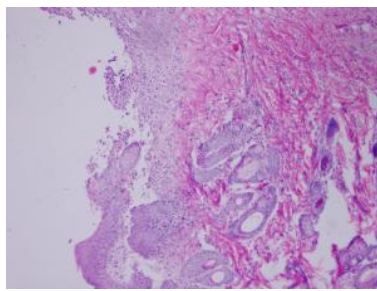

Picture 8 Medium doses of D group $\mathrm{HE} * 100$

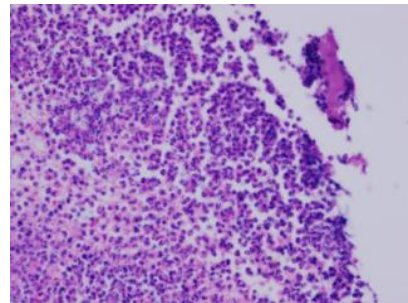

Picture 3 The model group $\mathrm{HE} * 400$

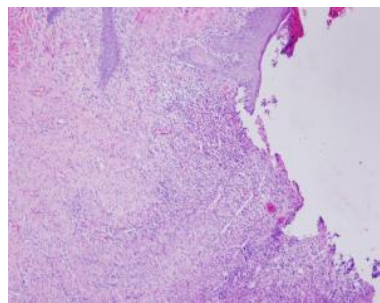

Picture 6 large dose of SD group $\mathrm{HE} * 100$

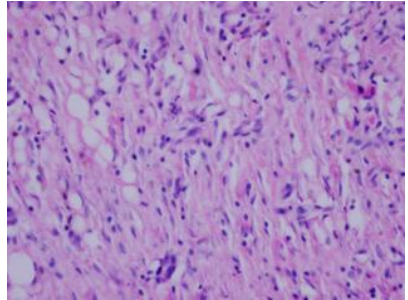

Picture 9 Medium doses of SD group $\mathrm{HE} * 400$

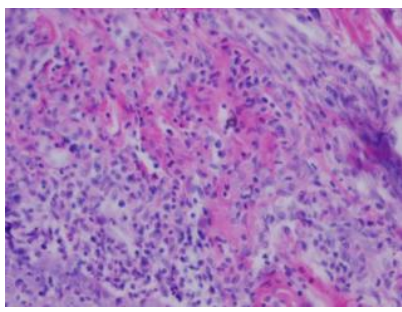

Picture 11 small dose of SD group group $\mathrm{HE} * 400$ 